Journal of Biotechnology and Strategic Health Research

Derleme / Review

http://dergipark.org.tr/tr/pub/bshr

\title{
Salgınlarda Toplum Davranıșı ve Sağlık Okuryazarlığı
}

\author{
Community Behavior and Health Literacy in Outbreaks
}

(iD) Seçil Özkan, (D) $₫$ Hakan Tüzün, (D) Asiye Uğraş Dikmen, (D) Mustafa Necmi İlhan

Gazi Üniversitesi Tip Fakültesi, Halk Sağlığı Anabilim Dalı

ORCID ID: Seçil Özkan 0000-0003-1572-8777, Hakan Tüzün 0000-0002-6376-8979, Asiye Uğraş Dikmen 0000-0002-3204-7562 Mustafa Necmi İlhan 0000-0003-1367-6328

^Sorumlu Yazar / Corresponding Author: Dr. Öğr. Üyesi Hakan Tüzün, e-posta / e-mail: drtuzunh@yahoo.com

Geliş Tarihi / Received : 13-04-2020 Kabul Tarihi / Accepted: 18-04-2020 Yayın Tarihi / Online Published: 30-04-2020

Atıf Gösterimi/How to Cite: Özkan S., Tüzün H., Dikmen A.U., İlhan MN. Salgınlarda Toplum Davranışı ve Sağlık Okuryazarlığı,

J Biotechnol and Strategic Health Res. 2020;1(Özel Sayı):105-110

Öz

Salgınlarda, insanların davranışsal tepkilerinin toplumsal sonuçları etkilediği görülmüştür. Acil müdahale için toplum bilimlerine dayalı yaklaşımları ve müdahaleleri entegre etmek önemlidir. Müdahalelerin toplum tarafından algılanması ve uygulanması ise bireylerin sağlık okuryazarlığı düzeyi ile yakından ilişkilidir. Bu derlemede salgınlarda birey davranış modelleri ve etkili faktörler incelenmiştir. Salgın esnasında uygulana kriz iletişiminin başarısında sağlık okuryazarlığının etkisine değinilmiştir.

Anahtar salgın, toplum davranışı, sağlık iletişimi, sağlık okuryazarlığı

Kelimeler

\begin{tabular}{|c|c|}
\hline Abstract & \\
\hline & $\begin{array}{l}\text { In outbreaks, human behavioral responses have been shown to affect social outcomes. For emergency intervention, it is important to integrate } \\
\text { approaches and interventions based on public science. The perception and implementation of interventions by the community is closely related } \\
\text { to the level of health literacy of individuals. In this review, individual behavior models and effective factors were examined in outbreaks. During }\end{array}$ \\
\hline
\end{tabular}

Keywords epidemic, community behavior, health communication, health literacy 


\section{GíRiş}

Pandemi, önemli morbidite ve mortaliteye neden olabilecek dünya çapında bir salgındır. Dünyada değişik dönemlerde büyük salgınlar olmuştur. 21. yüzyılda, bulaşıcı hastalık tehlikelerini tespit etmek ve yönetmek açısından yeni ve kalıcı zorluklar ortaya çıkmıştır: şiddetli akut solunum sendromu (SARS), grip ve Orta Doğu solunum sendromu (MERS), Ebola veya Zika gibi daha yeni sağlık acil durumlarına eklenebilecek örneklerdir. 2020 yılında da COVID-19 pandemisi tüm ülke ve toplumları etkilemektedir. ${ }^{1}$

Bu salgın ve salgınlarda, insanların davranışsal tepkilerinin toplumsal sonuçları etkilediği görülmüştür. Sağlıkla ilgili acil durumda, topluma dayalı müdahaleleri sistematik olarak dahil etme ihtiyacı farkedilmiştir. Acil müdahale için toplum bilimlerine dayalı yaklaşımları ve müdahaleleri entegre etmek, bilinen riskli davranışlarla ilgili temel sosyal ve kültürel verileri oluşturmak ve sağlık risklerini azaltmak için acil olmayan dönemlerde ve acil dönemlerde ülkelere uygulamak önemlidir. Bu müdahalelerin toplum tarafından algılanması, kabullenilmesi ve uygulanması ise bireylerin sağlık okuryazarlığı düzeyi ile yakından ilişkilidir. ${ }^{2}$ Sağlık okuryazarlığı, bireylerin sağlıkla ilgili bilgiye ulaşması, anlaması ve kullanması için gereken bilişsel ve sosyal beceri kapasitesi olarak tanımlanmaktadır. Toplumdaki sınırlı ve yetersiz sağlık okuryazarlığı aslında bir sessiz salgındır. Sağlık sorunlarının, salgınların ortaya çıkmasına ve salgın durumunda da çok önemli olan doğru sağlık davranışlarının yapılmasında, salgında toplum tepkilerinin oluşumunda önemlidir. ${ }^{3}$

Pandemiler karşısında, insanların enfeksiyon, bulaşma ve hastalık şiddetini azaltmak için nasıl davrandıklarını etkileyen faktörleri anlamak önemlidir. Bu anlayış, hastalığın etkisini ve yayılmasını en aza indirmeyi amaçlayan iletişim stratejilerini bilgilendirebilir. Bununla birlikte, bugüne kadar, insanların pandemik bir krize nasıl tepki verecekleri hakkında çok çalışma bulunmamaktadır. İnsanların olası tepkilerini öngören ve daha sonra bir pandeminin ortaya çıkması durumunda sonuçlarını sınırlayan etkili iletişim stratejileri ve davranışsal müdahaleler geliştirmek için, bireylerin sağlık okuryazarlığı düzeyi göz önüne alınmalıdır. $\mathrm{Bu}$ derlemenin amacı, yapılan çalışmalarla, salgınlarda birey davranış modelleriyle ve etkili faktörlerle ilișkiler kurmak, bunların politika ve uygulamaların uygulanmasını kolaylaştıracak kavramsal çerçeveler çizmektir.

\section{Salgınlar ve Toplumsal Davranışlar}

Pandemide toplumun davranışsal tepkileri üzerine bir dizi yaklaşım vardır. Koruma Motivasyon Teorisi (Protection Motivation Theory-PMT), Sağlık Inanç Modeli (Health Belief Model -HBM), Genişletilmiş Paralel Süreç Modeli (Extended Parallel Process Model-EPPM), Önlem Kabul Süreci Modeli (Precaution Adoption Process Model-PAPM), Transteorik Model (TM) gibi. ${ }^{4-7} \mathrm{Bu}$ yaklaşımların altında yatan temel fikir, insanların bir eylem gerçekleştirerek bir tehdide tepki vermeleridir. Tehdit değerlendirmesi, risk algısı ile ilgilidir.

Risk algısı ifadesi bir sağlık tehdidine karşı algılanan duyarlılık (susceptibility) olarak tanımlanır. Genellikle algılanan yaralanabilirlik/savunmasızlık (vulnerability) ve şiddet (severity) boyutlarından oluşur. Yaralanabilirlik ya da savunmasızlık; sağlık tehdidinden algılanan etkilenme olasılığ́ olarak tanımlanabilir.

Bunlar;

- $\quad$ algılanan yanıt etkinliği ("hangi koruyucu davranış yardımcı olacaktır?"),

- $\quad$ yanıt için algılanan öz yeterlik ("koruyucu davranışı gerçekleştirebileceğimden emin miyim?”)

- yanıtın dezavantajı ("koruyucu davranışın dezavantajları nelerdir?").

Risk algısı, başa çıkma değerlendirmesi, kullanılan eylem türünü belirlerken, davranışı gösterme niyetini harekete geçirir. Eylem uyarlanabilir ve tavsiye edilen koruyucu davranışların performtam yapılmasını veya tersine neden olabilir, böylece tavsiye edilenler dışındaki davranışların oluşumuna yol açabilir. Uygun davranışın oluşabilmesi için, algılanan şiddet ve duyarlılık ile yanıt ve öz yeterlik 
yüksek olmalı, yanıtın dezavantajları ise nispeten düşük kalmalıdır. Algılanan şiddet ve duyarlılık düşükse, insanlar konuyu tehdit edici olarak algılamaz ve sonuç olarak tavsiye edilen davranışı göstermeye meyilli olmayacaktır. Algılanan şiddet ve duyarlılık yüksekse ancak yanıt ve/veya öz yeterlik düşükse, uyumsuz tepkiler (örneğin bir tehdidin varlığını inkar etme) ortaya çıkabilir. ${ }^{8-9}$

Bir pandemide yanıt olarak gösterilen koruyucu davranışlar geniş ölçüde üç tipe ayrılabilir: önleyici, kaçınıcı ve hastalık davranışlarının yönetimi. Önleyici davranışlar arasında hijyen davranışları (el yıkama, el/dokuya öksürme veya hapşırma, yüzeyleri temizleme gibi); maske takma ve aşı uygulamalarıdır. Kaçınmacı davranışlar ise; kalabalık ortamlara girmeme, toplu taşıma kullanmama ve karantina kısıtlamaları ile çalışmaya uyum uygulamalarıdır. Hastalık davranışlarının yönetimi, antiviral ilaç vb tedaviye uyum, profesyonellerden yardım alma ve telefon/internet yardım hatlarını kullanmayı içerir. Bu davranışlardan bazıları, bireyin yerine getirme sorumluluğundadır, diğerleri ise kanunla belirlenir. Riski ve ciddiyetini algllama, uygun davranışı göstermede öz yeterlilik için bireylerin sağlık okuryazarlığı düzeyinin yüksek olması gereklidir.

Bugüne kadar, bir pandemiye yönelik davranışsal tepkilere odaklanan sınırlı sayıda çalışma mevcuttur. Biri Markel ve meslektaşları tarafından yapılan bir çalışmadır. Çalışmalarında, 1918 ve 1919 influenza pandemic sırasında ABD şehirlerinde uygulanan bir dizi ilaç dışı müdahalenin etkilerini tanımlamışlardır. Bunlar arasında okul kapanışları, halka açı yerlerde toplanma yasakları, izolasyon, karantina ve çalışma takvimi değişiklikleri, toplu taşıma kullanımı kısıtlamaları ve yüz maskesi düzenlemeleri gibi yardımcı müdahaleler yer almıştır. Bulguları, bu davranışsal müdahalelerin uygulanmasının gerçekten de bu pandeminin sonuçlarını sınırladığını öne sürmektedir. ${ }^{10}$

Bir başka çalışmada da hastalıkların algılanan duyarlılığının, algılanan ciddiyetinin daha yüksek seviyelerinin ve hastalığa karşı korunmak için önerilen davranışların etkinliğine olan inancın davranışın önemli belirleyicileri olduğunu saptanmıștır. Ayrıca, yasal düzenlemenin ve yetkililere daha fazla güvenin davranışla ilişkili olduğuna dair kanıtlar da bulunmuştur. Müdahale çalışmalarının ve iletişim stratejilerinin belirli demografik gruplara ve pandemik hastalığa yönelik algılanan tehdit seviyelerinin yükseltilmesine ve buna karşı korunmak için tasarlanan önlemlerin etkinliğine olan inancına odaklanması gerektiğini göstermektedir. ${ }^{11}$

Bazı çalışmalarda yaşlı bireylerin koruyucu önlemlere daha çok uyduğu saptanırken ${ }^{12-15}$, bazı çalışmalarda da yaş ile ilişki bulunamamıştır. ${ }^{16-18}$ Yine cinsiyet açısından da bazı çalışmalarda fark saptanırken, bazılarında saptanmamıştır. ${ }^{12-16,18}$ Genel olarak, daha eğitimli insanların koruyucu ve kaçınıcı davranışlar sergilemesi muhtemeldir, ancak bazı yayınlar bunun tersini de bulmuştur.

Leventhal, Meyer ve Nerenz (1980) tarafından geliştirilen hastalık sağduyu modeli, bireylerin aynı anda bir hastalığın bilişsel ve duygusal temsillerini oluşturdukları bir 'paralel işlem modeli' dir. Yeni bir tehditle karşı karşıya kaldıklarında, bireyler sorunu anlamak ve yönetmek için tehdidin zihinsel bir modelini oluştururlar. Temsil, hastalığın nedeni, sonuçları (hastalığın etkisi açısından), kimliği, zaman çizgisi ve kontrol edilebilirliği hakkındaki inançları içerir. ${ }^{19}$ Paralel bir duygusal tepki bu zihinsel modelle etkileşime girer ve bu tehditle ilgili başa çıma stratejilerini ve sağlık davranışlarını yönlendirir. 45 çalışmayı içeren bir meta-analiz, hastalık temsilleri ile başa çıma ve hastalık sonuçları arasındaki ilişkiyi inceledi. Bu, bu kavramlar arasındaki ilişkilerin model tarafından tahmin edilenlerle nasıl tutarlı olduğunu ve modelin çeşitli sağlık davranışlarını öngördüğünü göstermiştir. ${ }^{20}$

Genel olarak toplumun sağlık okuryazarlığı düzeyi ile ilişkilendiren çalışmalar yoktur. Ancak sağlık okuryazarlığını etkileyen yaş, eğitim durumu gibi sosyodemografik faktörler, salgınlarda bireylerin olumlu sağlık davranışı göstermesine etkisi ispatlanamamıştır. Bu sosyodemografik 
değişkenlerin sağlık okuryazarlığı düzeyi ile ilişkili olması, bireylerin sağlık okuryazarlığı düzeyinin salgınlardaki davranış modellerine etkilediğini düşündürmektedir.

\section{Salgınlar, sağlık iletişimi ve sağlık okuryazarlığı}

Salgın dönemlerinde iletişim her zamankinden önemli hale gelmektedir. Ortaya çıkan karmaşanın etkisini azaltmak ve sonrasında ise toplumun daha kolay ve hizlı toparlanmasına imkan sağlayabilmek bakımından iletişim kritik bir role sahiptir. Bu süreçteki iletişim de kriz iletişimi olarak adlandırılmaktadır. Kriz iletişimi “yaşanan krizi gerçeği ve alınan önlemlerin algılanmasına yönelik algılanmasına yönelik stratejiler geliştirilmesi ve uygulanması" olarak tanımlanmaktadır. Bu süreçte sağlık hizmeti veren kuruluşların toplumla ve işbirliği içinde bulunulan paydaşlarla düzenli ve sağlıklı iletişim içinde olmaları önem taşımaktadır. ${ }^{21}$

Kriz iletişimi yürütülürken dikkate alınması gereken temel noktalar şu şekilde sıralanmaktadır ${ }^{22}$ :

- Empati göstermek

- Riskleri basit olarak anlatmak

- Kişilere riski azaltmak ve güvende kalmak için yapmaları gereken şeyler hakkında bilgi vermek

- Kurumlar için kurumun olağanüstü durumla başa çıkma üzere yaptıkların anlatmak, kurumun bu konudaki faaliyetlerini nasıl devam ettireceği ve güncelleyeceği ile ilgili bilgiler vermek

- Toplumun zararları azaltmak üzere yapması gerekenleri ve riskleri anlamaya devam etmesini sağlamak

- Daha fazla arka plan bilgisi vermek

- Farklı toplumsal gruplara yönelik farklı riskleri anlatacak biçimde farklı toplumsal kesimlere seslenmek

- Cevaba yönelik kamu desteğini ve işbirliğini güçlendirmek

- Yanlış, söylentileri, doğru bilinen yanlışları belirlemek

Sağlığı belirleyen faktörlerden önemli ölçüde etkilenen, diğer yandan sağlık davranışlarının ve sağlık çıktılarının şekillenmesinde önemli bir belirleyici rolü oynayan sağlık okuryazarlı̆̆ı, olağan dönemlerde olduğu gibi, afet dönemlerinde de kriz iletişiminde etkisi dikkate alınması gereken önemli bir başlığa karşılık gelmektedir. Sağlık okuryazarlığı düzeyi ile ilgili araştırma çalışmalarının sayısında son birkaç on yıl içinde önemli artış dikkati çekmektedir. Ülkelerin kendi sağlık okuryazarlığı düzeylerini ulusal düzeyde saptamaları ve elde ettikleri verilere dayalı olarak sağlık okuryazarlığını geliştirmek üzere programlar üretmeleri sağlık politikalarının tavsiyeleri arasında yer almaktadır. Türkiye’de ise Sağlık Bakanlığı tarafından yürütülen bir çalışma ile sağlık okuryazarlığı düzeyinin değişimi ulusal düzeyde ortaya konmuştur. TSOY-32 ölçeği ile saptanan sağlık okuryazarlığı düzeyinin değişimine bakıldığında, \% 30,9’unun yetersiz, \% 38,0'ının sorunlu-sınırlı, \% 23,4'ünün yeterli, \%7,7'sinin ise mükemmel düzeyde olduğu görülmektedir. Araştırma ile sağlık okuryazarlığı yetersiz olanlarla sorunlu-sınırlı olanları kapayacak biçimde tanımlanan kısıtlı sağlık okuryazarlığının ülkedeki her on kişiden yedisini etkileyen önemli bir halk sağlığı sorunu olarak öne çıktığg saptanmaktadır. ${ }^{23}$

Avrupa Birliği üyesi sekiz ülkeyi kapsayan Avrupa Sağlık Okuryazarlığı çalışmasında \%12,4 yetersiz, \%35,2 sorunlu, \%36 yeterli ve \%16,5 mükemmel sağlık okuryazarlığı düzeyi saptanmıştır. ABD’de ulusal erişkin okuryazarlığı çalışmasına göre ise $\% 12$ yeterli, \%53 orta düzeyde, $\% 22$ temel düzeyde, \%14 temel düzeyde sağlık okuryazarlığı saptanmıştır. Türkiye \%30,9 yetersiz sağlık okuryazarlığı ile bu iki bölgedeki yetersiz sağlık okuryazarlığı düzeyinin yaklaşık iki katına sahiptir. Türkiye sonuçları Avrupa sağlık okuryazarlığı kapsamındaki ülkelerle karşılaştırıldığında ise Türkiye'nin bu grupta en kötü durumdaki ülke olan Bulgaristan'ın da gerisinde kaldığg görülmektedir. ${ }^{24,25}$

Türkiyede kısıtlı sağlık okuryazarlığının yaygınlığı toplumu diğer sağlık risklerine olduğu gibi bulaşıcı hastalıklara karşı da daha riskli hale getirmektedir. Pandemi sırasında Türkiye'deki sağlık okuryazarlığı düzeyinin akılda tutulması salgının yönetimine katkı sağlayabilir. Diğer yandan 
Sağlık Bakanlığı araştırmasının sonuçlarına göre kısıtlı sağlık okuryazarlığı olanlar toplumun genelinde yaklaşık her on kişiden yedisine karşılık gelirken yaşlılarda bu her on kişiden dokuza çıkmaktadır. Koronavirüsün özelikle yaşlılarda daha ağır ya da ölümcül ilerlediği göz önüne alındığında salgın esnasında sağlık okuryazarlığı bakımından dezavantajlı olan toplumsal gruplarla uygun iletişimi sağlayabilmenin önemi daha belirgin hale gelmektedir.

Salgın ortamında insan davranışlarını uygun şekilde yönlendirilmesi, tıbbi önlemlerin yanında yer alan anahtar faktördür. Sağlık kurumlarının sağlık okuryazarlığı ile ilgili ilkeleri dikkate alması, kolaylıkla anlaşılabilir ve uygulanabilir bilgiler vermesi, erişilebilir bilgi kaynakları oluşturması, salgının gidişini belirleyen faktörler arasında yer alacaktır. Toplumlarda kısıtlı sağlık okuryazarlığının yaygın olması nedeni ile bu zorlu bir uğraş olacaktır. Yanlış bilgiler ise mücadele edilmesi gereken bir başka önemli başlı̆ga karşılık gelmektedir. Sahte haberler toplumda korkunu yayılmasına neden olabilir. Koronavirüs salgını sırasında sahte haberlerin ya da doğrulanmamış bilgilerin twitter, facebook ya da whats app gibi sosyal medya kanalları üzerinden virüsten daha hazlı yayıldı̆̆ı belirtilmektedir. ${ }^{26}$

Öyle ki Dünya Sağlık Örgütü, 2019 korona pandemisine geniş çaplı bir “infodemi”nin eşlik ettiğini, bir kısmı doğru olan bir kısmı yanlış olan aşırı miktardaki bilginin yayılmasını ifade etmiş; bu durumun da kişilerin ihtiyaç duyduklarında güvenilir bilgi kaynaklarına ve güvenilir rehberlere erişimini oldukça zorlaştırdığını vurgulamıştır27 .

\section{SONUÇ}

Hastalıkların algılanan duyarlılığının ve algılanan ciddiyetinin daha yüksek seviyelerinin ve hastalığa karşı korunmak için önerilen davranışların etkinliğine olan inancın da davranışın önemli belirleyicileri olduğuna dair kanıtlar vardır. Ayrıca, kaygının daha yüksek seviyelerinin ve yetkililere daha fazla güvenin davranışla ilişkili olduğuna dair kanıtlar da vardır. Bu derlemeden elde edilen bulgular genel olarak sağlık davranışı teorileri ile açıklanabilir. Bununla birlikte, demografik faktörler, tutumlar ve davranış arasındaki ilişkiyi daha da netleştirmek için teorik olarak yönlendirilen prospektif çalışmalar gereklidir. Bulgular, müdahale çalışmalarının belirli demografik gruplara ve pandemik hastalığa yönelik algılanan tehdit seviyelerini yükseltmeye ve buna karşı korunmak için tasarlanan önlemlerin etkinliğine olan inancına odaklanması gerektiğini göstermektedir. Bu müdahale çalışmalarında da sağlık okuryazarlığı düzeyi ve buna uygun İletişim stratejileri, salgın kontrolünde öncelik verilmesi gereken konulardandir. 
J Biotechnol and Strategic Health Res. 2020;1(Özel Sayı):105-110

ÖZKAN, TÜZÜN, DIKKMEN, İLHAN, Salgınlarda Toplum Davranışı

\section{Kaynaklar}

1. World Health Organization What is a pandemic? World Health Organization https://www. who.int/csr/disease/swineflu/frequently_asked_questions/pandemic/en/. Accessed 7.4.2020

2. World Health Organization Risk communication World Health Organization. https://www. who.int/risk-communication/socialnet/en/. Accessed 7.4.2020

3. Ilona Kickbusch, Jürgen M. Pelikan, Franklin Apfel \& Agis D. Tsouros. Eds. Health literacy: the solid facts. World Health Organization. Regional Office for Europe. 2013

4. Norman P, Boer H, Seydel ER: Protection Motivation Theory. In Predicting health behaviour Edited by: Conner M, Norman P. Berkshire, UK: Open University Press; 2005:81-126.

5. Champion VL, Skinner CS: The Health Belief Model. In Health behaviour and health education; theory, research, and practice Edited by: Glanz K, Rimer BK, Viswanath K. San Francisco, CA: Jossey Bass; 2008:45-65.

6. Witte K: Fear as motivator, fear as inhibitor: Using the EPPM to explain fear appeal successes and failures. In The handbook of communication and emotion Edited by: Andersen PA, Guerrero LK. New York: Academic Press; 1998:423-450.

7. Weinstein ND, Sandman PM, Blalock SJ: The Precaution Adoption ProcessModel. InHealthbehaviourandhealtheducation; theory, research, and practice Edited by: Glanz K, Rimer BK, Viswanath K. San Francisco, CA: Jossey Bass; 2008:123-147.

8. De Hoog N, Stroebe W, de Wit JBF: The impact of vulnerability to and severity of a health risk on processing and acceptance of fear-arousing communications:Ameta-analysis. ReviewofGeneralPsychology 2007, 11:258-285.

9. Ruiter RAC, Abraham C, Kok G: Scary warnings and rational precautions: A review of the psychology of fear appeals. Psychology \& Health 2001, 16:613-630.

10. Markel H, Lipman HB, Navarro JA, Sloan A, Michalsen JR, Stren AM, Cetron MS: Nonpharmaceutical interventions implemented by US cities during the 1918-1919 influenza pandemic. JAMA 2007, 298:644-654.

11. Bish A., Michie S., Demographic and attitudinal determinants of protective behaviours during a pandemic: A review, British Journal of Health Psychology 15(Pt 4):797-824 - November 2010, British Journal of Health Psychology 15(Pt 4):797-824 - November 2010 Doi:10.1348/135910710X485826

12. Lau JT, Tsui H, Lau M, Yang X., SARS transmission, risk factors, and prevention in Hong Kong., Emerg Infect Dis. 2004 Apr;10(4):587-92.

13. Leung et al. The epidemiology of severe acute respiratory syndrome in the 2003 Hong Kong epidemic: an analysis of all 1755 patients. Ann Intern Med. 2004 Nov 2;141(9):662-73.

14. Quah Ve Hin-Peng, Crisis Prevention and Management during SARS Outbreak, Singapore Emerging Infectious Diseases, www.cdc.gov/eid, Vol. 10, No. 2, February 2004.

15. Tang, C.S.K., Wong C.Y. An outbreak of the severe acute respiratory syndrome: Predictors of health behaviours and effect of community prevention measures in Hong Kong, China American Journal of Public Health 9311 1887- 18882003
16. Lau, J. T., Yang, X., Tsui, H. Y., Pang, E. SARS related preventive and risk behaviours practised by Hong Kong-mainland China cross border travellers during the outbreak of the SARS epidemic in Hong Kong Journal of Epidemiology and Community Health $5812988-996$ doi:10.1136/jech.2003.0174832004.

17. Lau, J. T., Yang, X., Tsui, H. Y., Pang, E., Kim, J. H. SARS preventive and risk behaviours of Hong Kong air travellers Epidemiology and Infection 132 727- 736doi:10.1017/ S0950268804002225 2004

18. Brug, J. Aro, A. R., Oenema, A., Zwart, de, O., Richardus, J. H., Bishop, G. D. SARS risk perception, knowledge, precautions, and information sources, The NetherlandsEmerging Infectious Disease 108 1486-1489 doi:10.1007/s12529-008-9000-x 2004.

19. Petrie, K. J., Weinman, J. Perceptions of health and illness: Current research and applications Amsterdam Harwood 1997.

20. Hagger, M., Orbell, S. A meta analytic review of the common-sense model of illness representations Psychology and Health 18 141-184 doi:10.1080/088704403100081321 2003.

21. Eda Çetinkaya, Afet Durumlarında Sağlık Kuruluşları İçin İletișimin Önemi ve Yönetimi içinde editör: Hakan Altıntaş Acil ve Afet Durumlarında Sağlı Yönetimi, Hacettepe Üniversitesi Yayinları Ankara 2013.

22. Center for Disease Control and Prevention. CERC Manuel. Crisis and Emergency Risk Communication. https://emergency.cdc.gov/cerc/manual/index.asp. Accessed 5.4.2020.

23. TC Sağlık Bakanlğ̆ı Sağhlğın Geliștirilmesi Genel Müdürlüğü Türkiye Sağlk Okuryazarlğ̆ Düzeyi ve İlişkili Faktörleri Araştırması Yayın No 1103 Ankara 2018.

24. Sørensen K, Pelikan JM, Röthlin F et al. Health literacy in Europe: comparative results of the European health literacy survey (HLS-EU) European Journal of Public Health, Volume 25, Issue 6, December 2015, Pages 1053-1058.

25. Kutner, M., Greenberg, E., Jin, Y. et al. eds. The Health Literacy of America's Adults: Results From the 2003 National Assessment of Adult Literacy (NCES 2006-483). U.S. Department of Education. Washington, DC: National Center for Education Statistics. 2006.

26. Orkan Okan, Kristine Sørensen, Melanie Messer. Coronavirus Needs: How to Become a Health Literate Society. nationalinterest.org https://nationalinterest.org/blog/buzz/coronavirus-needs-how-become-health-literate-society-135382. Accessed 5.4.2020.

27. Chia-Yi Hou. WHO warns of coronavirus 'infodemic' - an epidemic of too much information. https://thehill.com/. https://thehill.com/changing-america/well-being/prevention-cures/481387-were-in-an-infodemic-with-too-much-information Accessed 5.4.2020 